the time tin emptying itself, but it is only double that time, which demonstrates the statement.

A complete logical explanation of the action of the pneumo. gastric can be given on this theory, by assuming that its function consists in diminishing the calibre of the small arteries of the coronary system, and always keeping them somewhat contracted.

\section{PHENOMENA OF COAGULATION IN FROG'S BLOOD*}

I WAS endeavouring in the autumn of last year, at Prof. Sanderson's instigation, to demonstrate upon the frog some of Briicke's fundamental experiments on the coagulation of the blood, which he performed on the tortoise; I was surprised at the apparent failure of some of them. For instance, having tied a glass tube into the animal's aorta and allowed it to fill with blood, I expecked that which was in the tube speedily to coagulate, that which remained in the lieart to continue liquid for a considerable time. But no such contrast was observable, both portions of blood remained perfectly fluid for an indefinite time. I say apparently, for, in fact, on subsequently turning out the blood, a slight film of coagulated fibrin was observable attached to the walls of the tube. Of course the corpuscles being the heavier gravitate to the bottom, and the blood thus becomes divided into two portions, a clear fluid above and a mass of red corpuscles below, with a thin filmy stratum of white again on the surface of the latter.

To show that the clear fluid is plasma and not merely serum, that is to say, that it fully retains its coagulability, it is sufficient to take a little up into a very fine, almost capillary, glass tube. The extent of surface to which it is thus exposed very quickly determines its coagulation.

Following up the subject still further, I found the same thing to happen when the blood is allowed to drop into a glass vessel, the whole remaining fluid, except that portion in immediate contact with the sides, the corpuscles subsiding as before, and the supernatant liquid being readily coagulable in a capillary tube.

But frogr's blood does not always behave in this manner. It is not unfrequently the case, especially at this season of the year, that the blood of these animals behaves to all appearance precisely as we are in the habit of expecting that blood should behave, that is to say, the commencing subsidence of the corpuscles is arrested, the fluir solidifies, seemingly throughout. And, incleed, in rare instances, the coagulation is complete to the centre, and the mass soon separates into clot and serum, which latter, in these cases, never yields a coagulum in a capillary tube. More frequently, however, on breaking the surface with a knife, the interior of the coagulated mass is seen to be occupied by still fluid blood.

In either case, the coagulated fibrin soon begins to contract and this contraction proceeds to such an extent that not only is the serum of the blood expressed from it, but it comes to pass that there is no longer room in its meshes for the involved corpuscles, which conseguently begin to be squeezed out and to fall to the bottom of the glass. This diminution in volume of the clot may proceed so far that in the course of a few hours the blood may present an appearance precisely as if it had not undergone coagulation at all, there being a mass of corpuscles at the bottom of the vessel, and a clear supernatant fluid. The contracted remains of the clot may however be always found, although often obscured by the liberated corpuscles. Now, this disappearance of the clot of frog's blood under certain circumstances was noticed some years ago by v. Reclinghausen, and ascribed by him to a re-liquefaction of the fibrin; and not un naturally, if we consider the astonishing diminution in bulk which it undergoes, and the fact that the serum in such cases is frequently found to yield a further coagulum.

But in every case of the latter kind, i.e. in every case in which the supernatant fluid yields a coagulum in a capillary tube, it will have been found that the primary coagulation was incom. plete, i.e. that the central parts of the blood remained fluid, whereas on the other hand it is certain that when the primary coagulation has been complete, no further coagulum is ever obtainable, although, in this case also, the clot may have contracted to a relatively exceedingly small bulk, in fact, may have almost disappeared.

A further proof, if one were needed, that the diminution of the *i:Paper read beforc the British Association at Brighton in Section $D$. (Deparment of Anatomy and Physiology), by E. A Schäfer, M.B. clot is due merely to contraction and not re-lique is to be found in the examination under the microsive asis $\mathrm{km}$ immersion objective, of the process as it occurs in a ro th: walled and fine capillary glass tube.

The phenomena here observed are wholly those vi wattistiva: first simply serum, then white corpuscles, and fin.... ret an puscles being expressed, until a mere thread of fivm rimaits almost obscured by the corpuscles and still includin: $*$ few.

Throughout the whole process, however, there is $m$ trive on a re-liquefaction of fibrin; this would of conse intwe the dropping away of the corpuscles from the sides; m the wntrity. they are most evidently squeezed out, some of them beins actually ruptured in the passage and appearing on the exterior of the clot as small reddish spheroids. The facts ster:, brictis, are these: that frog's blcod, especially if taken durins the winter months, exhibits but very little tendency to coagulatis. with the exception of the portion in immediate contact with : foreign surface; that, when apparently coagulater thrught out, the central portions are very apt to remain thais, and to impart coagulability to the expressed serum; that the lot wher formed frequently tends to attain a relatively very small bulk : and, finally, that this diminution in bulk is due to sumtraction merely, not reliquefaction of the fibrin.

\section{PHYSICS}

Acoustic Experiments on the Seine during the Siege of Paris

In the experiments made by Coliadon and Sturm an the lake of Geneva, in 1827 , to determine the velocity of somin in water, the source of sound was a bell, weighing sixty-five kilngrammes, fixed to a boat immersed in the water near kille. Inother boat, moored near Thonon, carried the observers, whe cmuly a long acoustic tube made of metal, ore extiemity of which, widened and closed with a membrane, was thrust ine : the wator. The distance from Rolle to Thonon is about 13,50 ntwits, so that the range of the sound was considerable. Plic watcr in that part of the lake is of great depth.

Durirg the siege of Paris, the idea arose of cstahishus sun acoustic telegraph by means of the Seine, betwen the invested city and provinces that had not been invaded. The lichera experiments appeared to favour the proposal.

M. Lucas was charged by the Minister of Public Wirks to make some experiments on the subject, which he :acindingly' did in November, IS7O. He gives an account of these fo the Paris Academy.

In the first series, a bell weighing forty kilogrammes was lowered by a windlass from the bow of a barce, io a pusition twenty or thirty centimetres from the bottom. It comisincd it clapper, which was moved by means of wires carrich up wo the barge. Two workmen were charged to ring the lill at cortain fixed intervals, while the observers, in another buat, winhert the effect at different distances, being carried alonir ly tha curtent. The acoustic tube employed was $1 \cdot 50 \mathrm{~m}$. long, and the membunc: of its orifice, immersed in the water, was turned fowarts the bell. At the distance of a few metres, a dull sound was heart (like that of a drum beat with a drum-stick), at each struke given to the bell. The intensity diminished with the distunce, and the sound ceased to be perceptible at about 1,800 metres. Th: result was constant for experiments repeated at different parts of the river.

In a second series of experiments, a bronze bell, weighing 354 kilogrammes, was used. This was hung in a worklen frame weighing 446 kilogrammes, constructed in the form of a cuatrangular pyramid. The hammer of the bell weighed sixten kilogrammes, and was moved by wires, as in the other case. The frame and bell were suspended by chains from the four corners, between two barges, and then lowered into the watcr. The mode of observation was the same as in the former case.

A few metres from the barge a slight metallic sound was heard, doubtless from the acoustic tube vibrating with the membrane. The sound soon became dull, its intensity decreased rajidly with the distance; at $I, 400$ or 1,5 co metres there was no perception of it.

Comparing these experiments with those of the fist series, we have the unexpected result that the very intense sound of a bell weighing 354 kilogrammes, has a less range than the weaker sound from a bell of forty kilogrammes.

In a third series, a small bell, twelve centimetres diamcter, was sounded in the water alternately with the bell of forty kilo. 